\title{
VERIFICATION OF COMBINED CUTTING TOOL WiTH A Linear CUTTING EdGe TOOL
}

\author{
Jozef Nosal', Katarína Brezíková \& Vladimír Simkulet
}
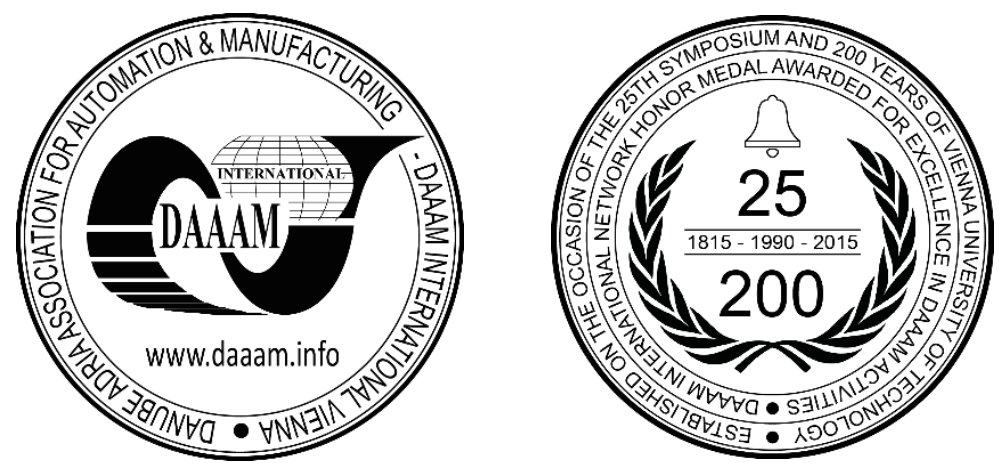

This Publication has to be referred as: Nosal, J[ozef]; Brezikova, K[atarina] \& Simkulet, V[ladimir] (2017). Verification of Combined Cutting tool with a Linear Cutting Edge tool, Proceedings of the 28th DAAAM International Symposium, pp.1227-1233, B. Katalinic (Ed.), Published by DAAAM International, ISBN 978-3-902734-11-2, ISSN 1726-9679, Vienna, Austria

DOI: $10.2507 / 28$ th.daaam.proceedings.171

\begin{abstract}
This article discusses how to increase the productivity of machining-turning when changing tool geometry and using an integrated experimental tool that consist from both roughing and finishing in one operation. In the first part there is a brief overview of the problem., in this part is described the patent file from Escher and Lindl, which consisted in creating a second tip that aligns the roughness created by the first tip Another solution is Wiper technology, which is now widely used to ensure maximum surface quality. The second part of this article deals with experimental tests carried out on the universal lathe SU 50, the workpiece material is 100CrMn6. The first experiment compared the quality of surface, using an integrated tool for roughing (tip radius: $r_{\varepsilon}=0,8 \mathrm{~mm}$ ) and finishing (tip radius: $r_{\varepsilon}=6 \mathrm{~mm}$ ). Results of the experimental showed improvement in quality of machined surface, but in higher feed rate the quality gradually increased. In the second experiment, the integrated tool was compared with cutting tool with oblique cutting edge, with rake angle $\lambda_{\mathrm{s}}= \pm 45^{\circ}$. The results showed that the quality of machined surface has improved throughout entire feed rate even at higher feed rates using tool with rake angle $\lambda_{\mathrm{s}}= \pm 45^{\circ}$.
\end{abstract}

Keywords: turning; integrated cutting tool; feed rate; oblique cutting; rake angle

\section{Introduction}

Present engineering production is characterized by rising level of automation, the incoming application of new, generally light and high strength materials that are technologically demanding to process. This results in a significant impact on the productivity of the production and the quality of the machined surface. Automation has greatly reduced the lead times and cutting tools manufactures are trying to improve surface quality by varying tool geometry adjustments. Therefore, the contribution is an example of a proposal for the improvement of technological methods, specifically turning [8], [7].

The influence of technology on the manufacturing process was dealt by some authors [4], [5], [6], in this paper, questions are asked about technologies to improve the quality of machined surface at high feed turning, comparing special tools with differ tool geometry. This comparing will lead to find optimal cutting tool with specific tool geometry for high feed turning. 
The following two examples are a selection of solutions for improving the quality of the machined surface during turning when changing tool geometry.

The first solution was submitted by Escher and Lindl [3] according to

Fig. 1. The solution consists in creating another tip that aligns the machined surface created by the first tip. The position of the second point is defined by the distance (1), where $n$ is an odd positive number. This causes the second point to reach the largest elevation of the surface formed by the first wedge. The disadvantage of such a solution is the complicated tip sharpening. There is also uneven wear of both spikes [3].

$$
k=\frac{n . f}{2}
$$

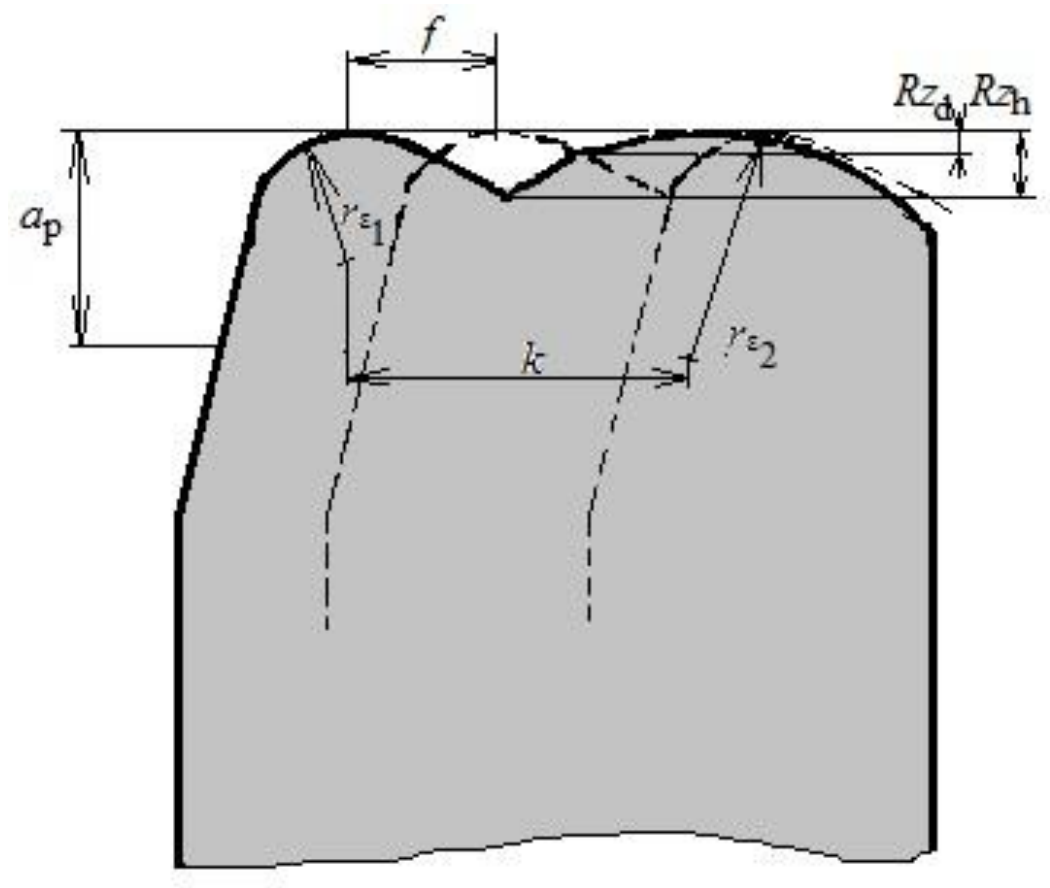

Fig. 1. Tool with two tip radius [3]

One of the other options is a technology which is focused on increasing productivity by adjusting the geometry of the cutting plate-

Fig. 2. with this it is possible to increase the quality of machined surface by the same displacement [9].

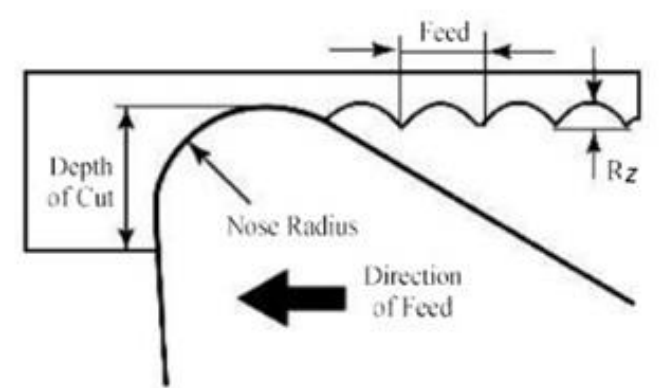

Geometry of Conventional Insert

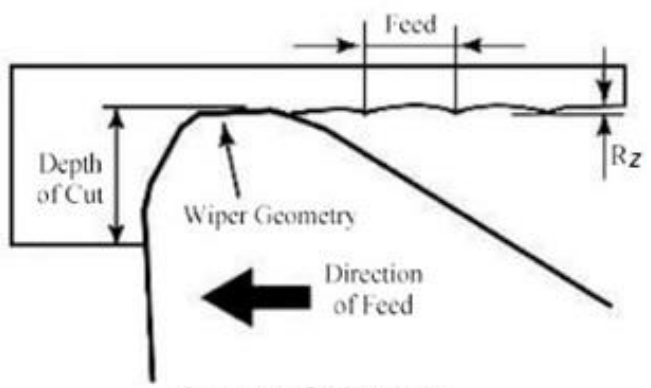

Geometry of Wiper Insert

Fig. 2. Difference between conventional and wiper insert cutting tool nose radius [10], [11]

The principle of Wiper improving the quality of machined surface in the same displacement, its means, that with same displacement is obtained the twice quality of the surface as well as achieve better different cutting splinters. The service life of the cutting edges is often improvement due to the reduction in the time in the cut, the consequence leads to cost savings [1], [2].

Wiper technology has a wide range of applications to ensure maximum productivity. When changing parameters during cutting are also available alternative Wiper plates which improve the quality of finishing surface and eliminating expensive grinding operations [9]. 


\section{Used machine and measuring instrument for roughness measurement}

For this experiment, was selected workpiece material 100CrMn6. The machine for performing the experiments was the Universal lathe SU 50- Fig. 3. To measure the surface roughness, the Mitutoyo Surfest SJ-301 was used- Fig. 4.

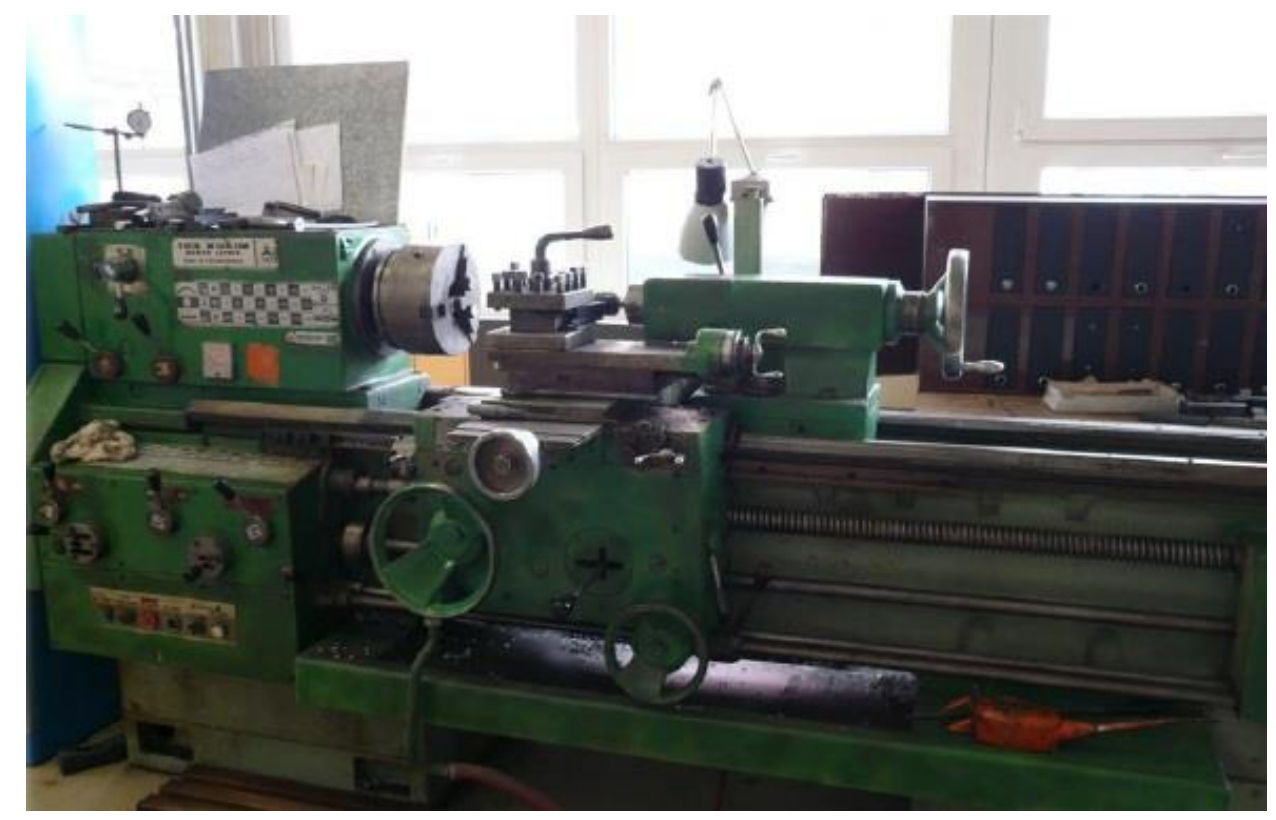

Fig. 3. Universal Lathe machine SU 50

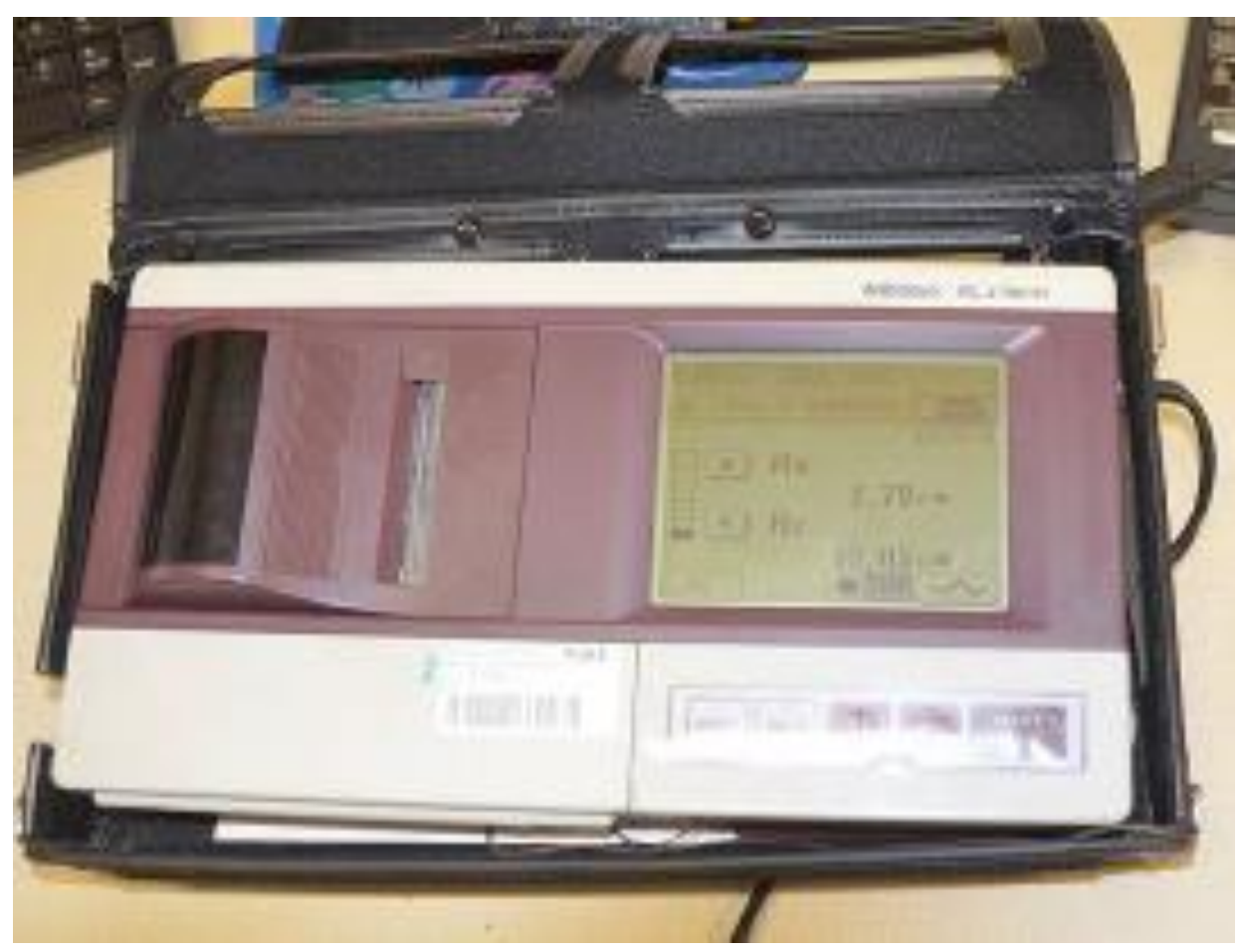

Fig. 4. Mitutoyo roughness meter

\section{Experimental setup}

For these experiments, two tools were selected. The first tool is integrated cutting tool with two nose radius. With this tool will test the quality of machined surface at higher feed rate. Experimenting conditions: Depth of cut $a_{\mathrm{ph}}=1 \mathrm{~mm}$, tip radius $r_{\mathrm{eh}}=0,8 \mathrm{~mm}$, the finishing tool worked at a depth of cut $a_{\mathrm{pd}}=0,2 \mathrm{~mm}$ and a tip radius was $r_{\mathrm{ed}}=6 \mathrm{~mm}$.

Second tool is cutting tool with linear cutting edge with rake angle $\lambda_{\mathrm{s}}= \pm 45^{\circ}$. This tool will be compared with integrated cutting tool for purposes of surface quality at higher feed rate. 


\subsection{Verification of integrated tool for turning}

In Fig, 5. is shown an experimental cutting tool and in Fig. 6. the principle of operation of this tool.

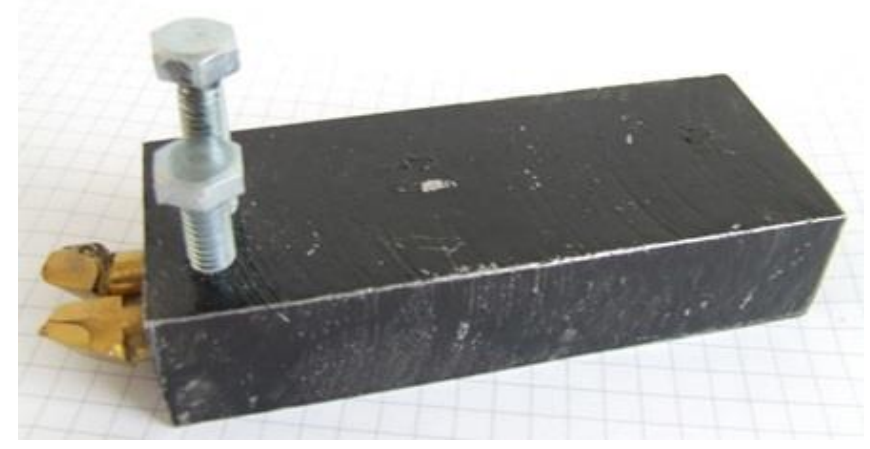

Fig. 5. Experimental integrated cutting tool

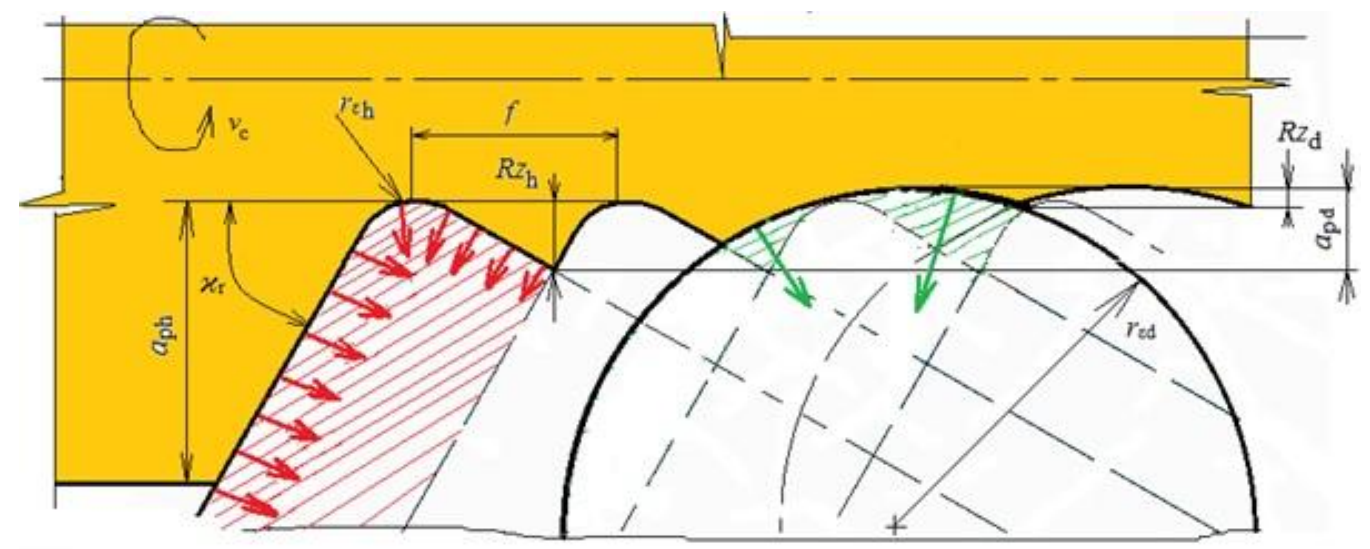

Fig. 6. Scheme of roughing and finishing using integrated cutting tool: $v_{\mathrm{c}}-$ cutting speed, $f$ - feed rate, $a_{\mathrm{ph}}-$ depth of cut after roughing, $a_{\mathrm{pd}}-$ depth of cut after finishing, $r_{\mathrm{eh}}-$ tip radius for roughing, $r_{\mathrm{ed}}-$ tip radius for finishing, $R z_{\mathrm{h}}-$ surface roughness

From the Fig. 6 is see, that in the first the tip radius for roughing $r_{\varepsilon h}$ we can see on the points of the cutting edge velocity vectors. The chip wants to get in perpendicular way to cutting edge because the cutting edge has a tip radius. By counting every single velocity vector we get the outcome of final velocity vector of movement of chip. First tool work is under the condition of bound rust. The depth of cut of second tip radius $a_{\mathrm{pd}}$ is equal or slightly larger than $R z_{\mathrm{h}}\left(a_{\mathrm{pd} \geq} R z_{\mathrm{h}}\right)$. In this case, the finishing tool $r_{\text {ed }}$ removes all the roughness created by the first tip radius $r_{\text {eh. }}$ With the finishing tool, the direction of the chip is identical with direction of movement of individual elements of chip. This case responds to the terms of the free cut, because the higher the tip radius is, and then is higher possibility for achieving free cutting conditions. The results of the experiment are shown in Fig. 7.

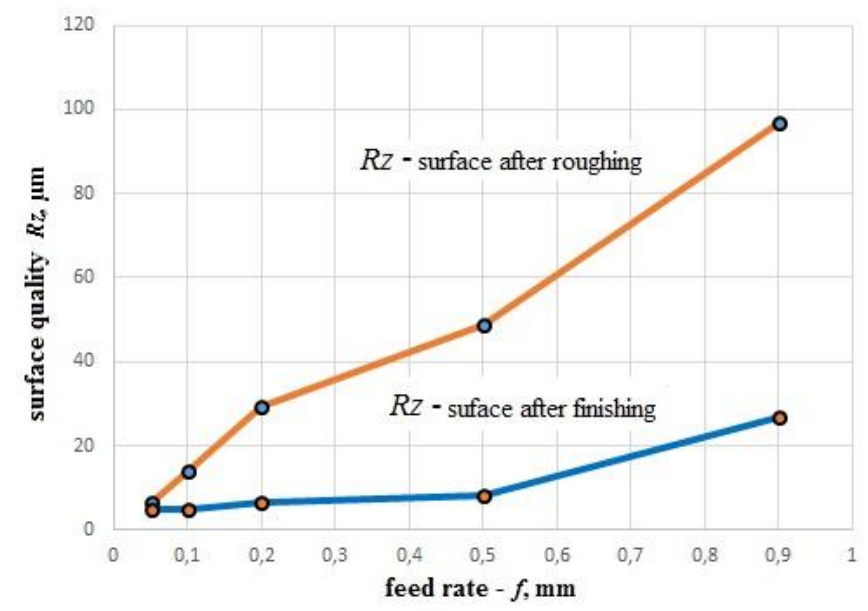

Fig. 7. Experimental results of Rz-f $(f)$ by applying integrated turning 
It can be seen from Fig. 7. that using the experimental tool improves the quality of the machined surface when finishing. At the lowest displacement, the $R z$ value do not differ significantly, changing from $0,1 \mathrm{~mm}$. With the increase in feed rate, surface quality deteriorates using a tool with $r_{\mathrm{eh}}=0,8 \mathrm{~mm}$, it improves with finishing tip radius $r_{\mathrm{ed}}=6 \mathrm{~mm}$.

From this experiment, using a large tip radius, in this case $r_{\mathrm{ed}}=6 \mathrm{~mm}$, results in a better machined surface at higher feed rates compared to a smaller tip radius $r_{\mathrm{eh}}=0,8 \mathrm{~mm}$. It can be argued that the larger the tip radius is, than we are approaching conditions of free cutting. However, the problem of increasing the tip radius is that leads to reduce the thickness of the cut layer, which can lead to the oscillation of the technological system.

This problem can be solved by the inclination of the rake angle $\lambda_{\mathrm{s}}$. The following chapter compares this tool with an integrated tool for turning.

\subsection{Verification of integrated tool for turning with a linear cutting edge tool with rake angle $\lambda_{s}$}

In this experiment, the same workpiece material and the same technological conditions were used. In Fig. 9. are results of the experiment. The tool is shown in Fig. 8.

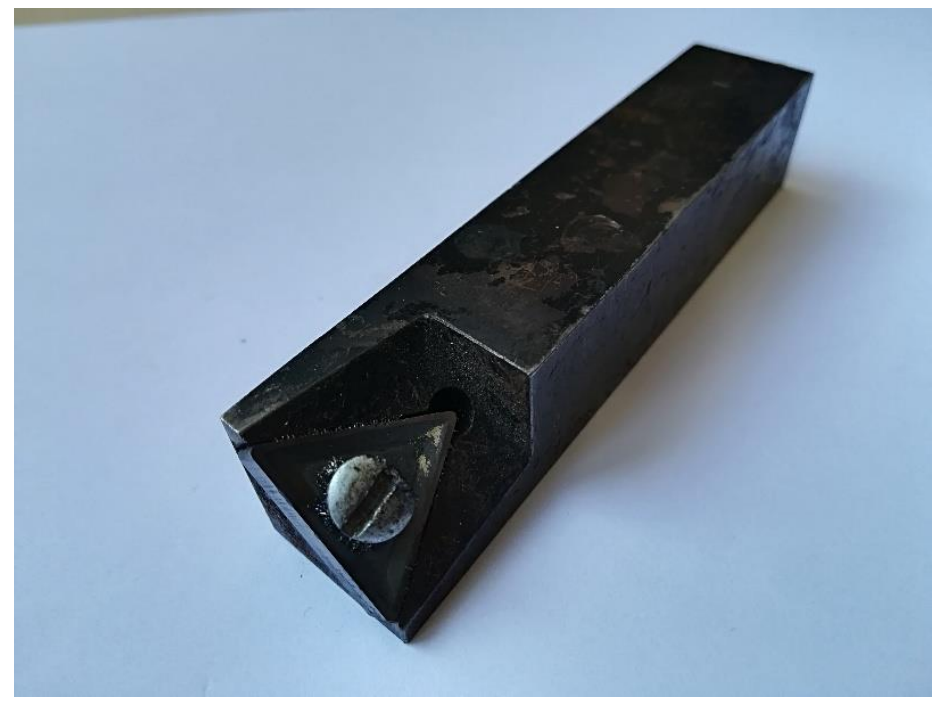

Fig. 8. Tool with a linear cutting edge with rake angle $\lambda \mathrm{s}= \pm 45^{\circ}$

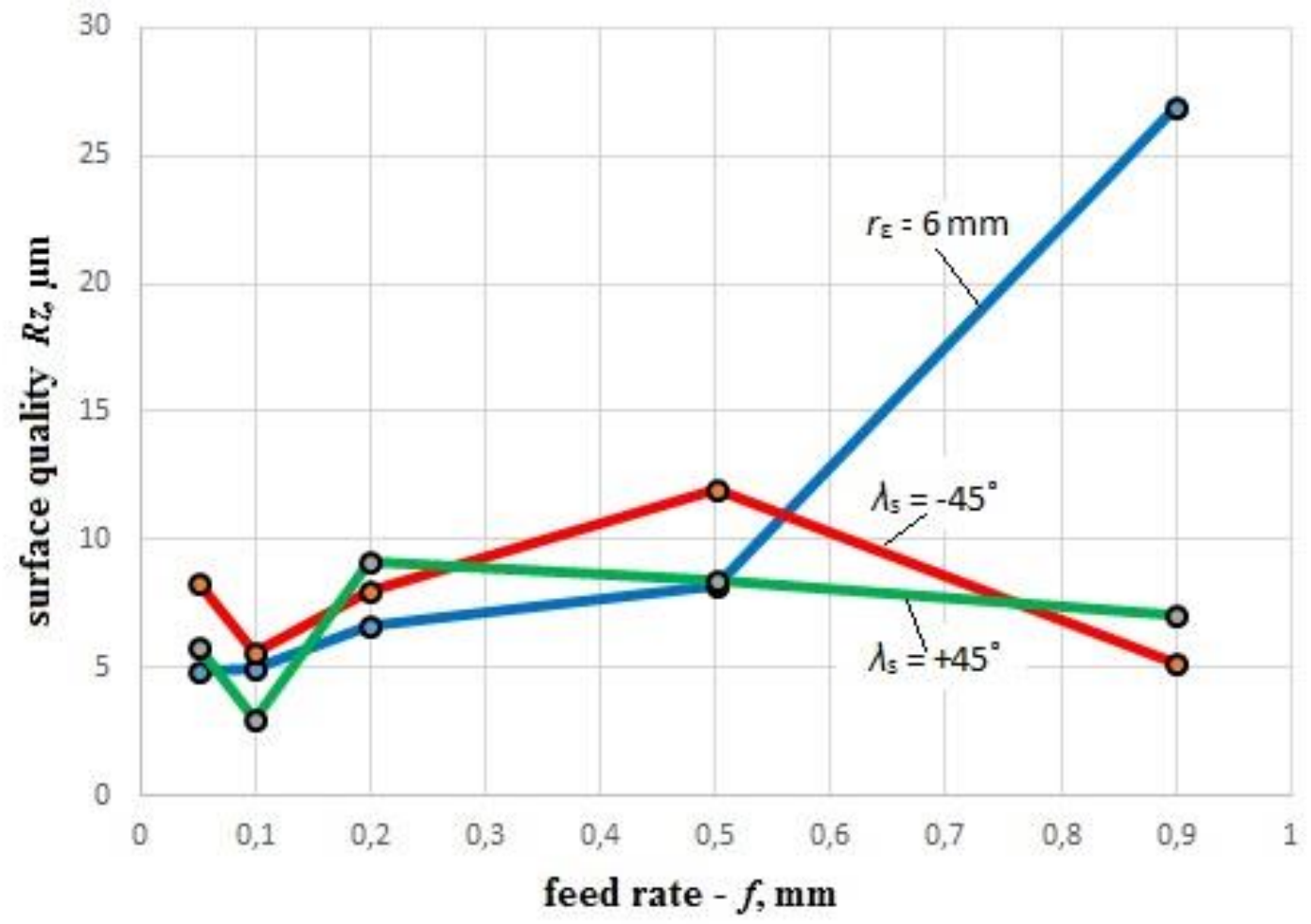

Fig. 9. Experimental results using a linear cutting edge with rake angle $\lambda_{\mathrm{s}}$ and a tool with large tip radius $r_{\varepsilon}=6 \mathrm{~mm}$ 
It can be seen from Fig. 9. that when the tool is used $r_{\varepsilon}=6 \mathrm{~mm}$, the quality of machined surface deteriorates at $f=0,5$ $\mathrm{mm}$. Vice versa, when using a linear cutting edge tool with rake angle $\lambda_{\mathrm{s}}= \pm 45^{\circ}$, quality improvement can be monitored, especially in the area of higher feed rate.

\subsection{Experimental design of integrated turning tool with linear cutting edge}

When applying a tool with an extremely large tip radius at a large feed rate, there is a problem that such a tool can not be used at high depth of cut. There is an increase in the length of the cutting edge in the engagement and the generation of vibration of the whole technological system- machine, tool and workpiece.

The possibility of solving this problem lies in the application of integrated tool for turning Fig. 10. This tool will work at a large feed rate and the finishing cutting edge with rake angle $\lambda_{\mathrm{s}}= \pm 45^{\circ}$ will be working in slightly higher depth of cut than the first cutting edge with smaller tip radius.

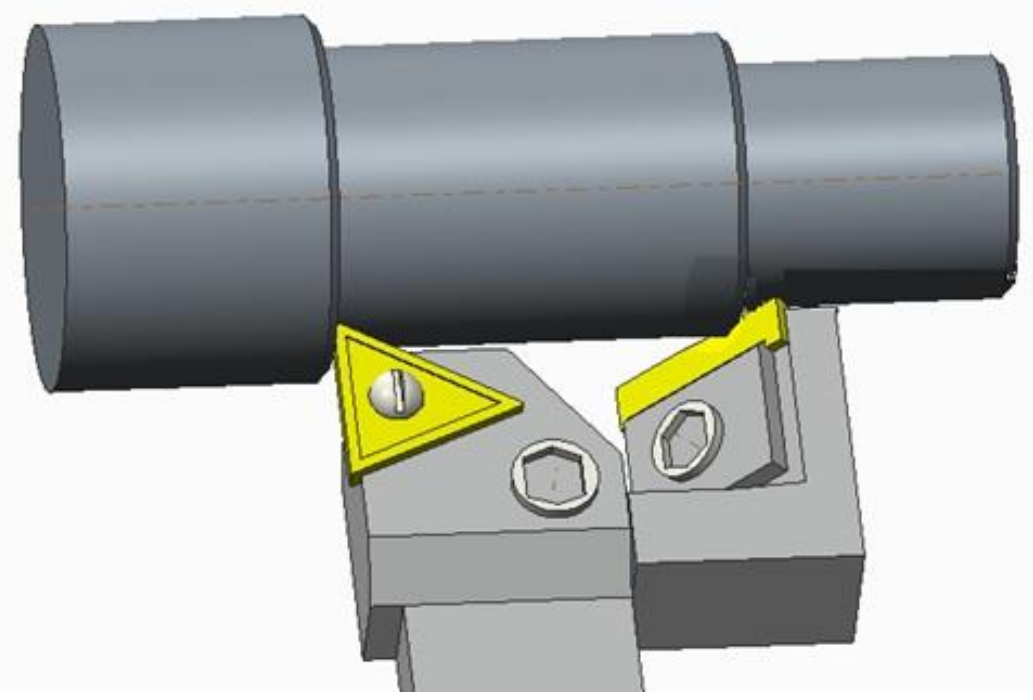

Fig. 10. Principal scheme of roughing and finishing in one operation, using secondary cutting edge with rake angle $\lambda s$

\section{Conclusion}

This work analysed the use of an integrated cutting tool for turning, which consisted of two tips. The first tip radius was smaller and served as a roughing, and the second tip radius was larger. The experiments performed with this tool pointed to the improvement of the machined surface, but at higher feed rate the quality deteriorated quadratic, which this can be as negative aspect for high feed turning.

To improve the quality of the machined surface at higher feed rate, for high-shear machining, it is possible to use a tool with a linear cutting edge with rake angle $\lambda_{\mathrm{s}}= \pm 45^{\circ}$. The experiments performed with this tool have pointed to improving the quality of machined surface, especially in the area of higher feed rate.

These experimental tests were performed on a conventional lathe machine, so further experimental testing would be appropriate on CNC machines and use this kind of tool for other frequently used materials in manufacturing practice.

For future research on improving machined surface using these two tools, it will also be necessary to track the wear of cutting edges for machining with higher feed rate and to monitor the quality of machined surface at a certain degree of wear, this allow for precise design of the material for the cutting inserts under given machining conditions on different materials in manufacturing practice.

\section{Acknowledgments}

This research work was supported by the Cultural and Educational Grant Agency of the Ministry of Education, Science, Research and Sport of the Slovak Republic (KEGA No.036TUKE-4/2017).

\section{References}

[1]. Abbas, A. T. M. (2016). Comparative Assessment of Wiper and Conventional Carbide Inserts on Surface Roughness in the Turning of High Strength Steel, Journal of Materials Science Research, Vol.5, No.1, 2016, pp.32-45, ISSN 1927-0585, DOI: 10.5539/jmsr.v5nlp32

[2]. Astakhov, V. P. (2010). Geometry of single-point Turning Tools and Drills Fundamentals and Practical Applications, Springer. Vol.22. p.565. ISBN 978-2-84996-052-6 
[3]. Esher, S.; Lindtl, K. (1976). Verfahren und Vorrichtung zur spananhebenden. Werkstatt und Betrieb, West German Patent No.2610097

[4]. Novak-Marcinčin, J.; Barna, J.; Nováková-Marcinčinová, L. \& Fečová, V.(2011). Principles of Product Assembly Visualization by Augmented Reality Usage, In: Annals of DAAAM for 2011 \& Proceedings of the 22nd International DAAAM Symposium on „Intelligent Manufacturing \& Automation: Power of Knowledge and Creativity“: 23-26th November 2011. Vienna, Austria. Vienna: DAAAM, 2011 P. 1049-1050. ISBN 978-3-90150983-4. ISSN 1726-9679

[5]. Orlovský, J.; Zajac, J.; Monka, P.P.; Michalik, P. \& Simkulet,V.(2011). Mathematical modelling of spray drying technological process. In Annals of DAAAM for 2011 \& Proceedings of the 22nd International DAAAM Symposium on „Intelligent Manufacturing \& Automation: Power of Knowledge and Creativity“: 23-26th November 2011. Vienna, Austria. Vienna: DAAAM International, 2011 P. 1067-1068. ISBN 978-3-901509-83-4. ISSN 17269679

[6]. Simkulet, V.; Hatala, M.; Orlovský, I.; Zajac, J.; Monka, P.P. \& Michalik, P.(2011). Microhardness evaluation of steel EN S233J2G3 in heat affected zone after plasma ARC cutting. In Annals of DAAAM for 2011 \& Proceedings of the 22nd International DAAAM Symposium on „Intelligent Manufacturing \& Automation: Power of Knowledge and Creativity“: 23-26th November 2011. Vienna, Austria. Vienna: DAAAM International, 2011 P.1103-1104. ISBN 978-3-901509-83-4. ISSN 1726-9679

[7]. Trent, E. M.; Wright, P.K. (2000). Metal cutting. Butterworth Heinemenn. Boston. p. 446. ISBN 0-7506-7069-X

[8]. Vasilko, K.; Vasilková, D. (2000). Metódy zlepšovania morfológie povrchov súčiastok. ISBN 80-7099-495-9. Prešov

[9]. Wiper. Sandvik Coromant. [online]. 2017. Available at: http://www.sandvik.coromant.com/plpl/knowledge/general_turning/getting_started/choice_of_insert/wiper

[10]. Kiyak, M.; Sahin. I. \& Cakir. O. (2016). Application of wiper insert in cutting tool technology. Proceedings of 1st ICAS 2016. Istanbul. $\quad$ pp. $\quad 60-65, \quad$ Available at: https://www.researchgate.net/publication/307964609_APPLICATION_OF_WIPER_INSERT_I_CUTTING_TOO L_TECHNOLOGY

[11]. http://artwi.blogspot.sk/2005/04/wiper-inserts-for-turning.html. Access in October 2017 